
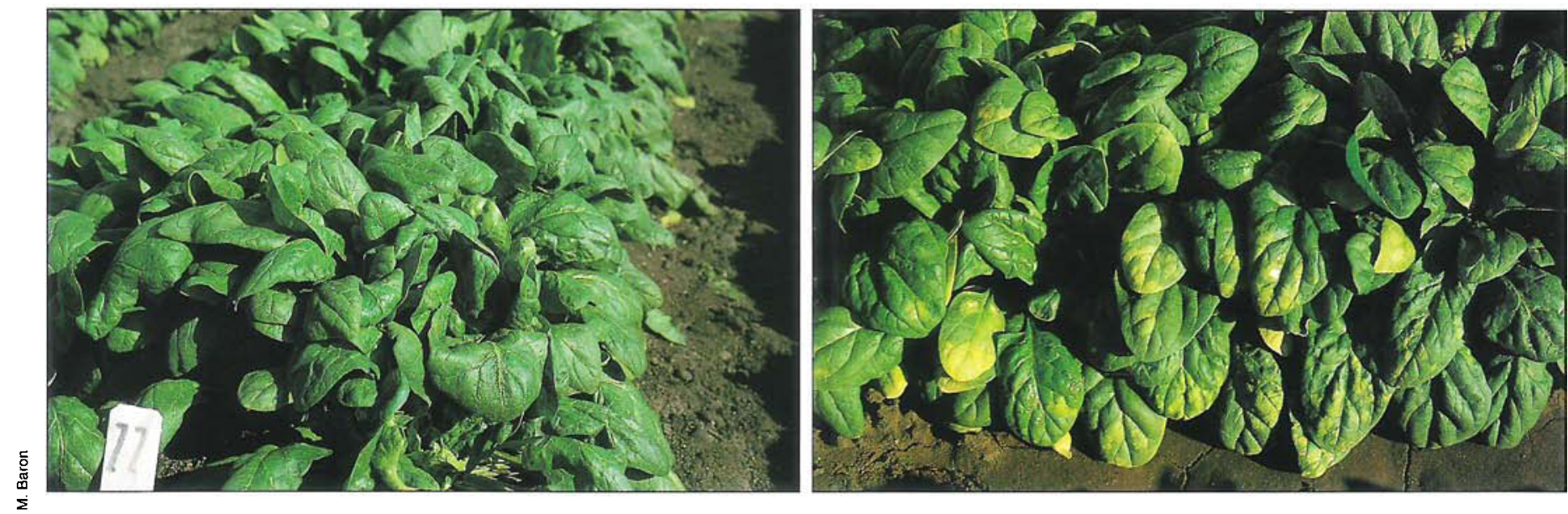

Shown above is 'Bossanova' cultivar, which showed resistance to downy mildew.

Above, 'Polka' cultivar with downy mildew infection.

\title{
Resistant cultivars, fungicides combat downy mildew of spinach
}

\author{
Steven T. Koike $\square$ Richard F. Smith $\square$ Kurt F. Schulbach
}

\section{The recent outbreak of spinach downy mildew, caused by a new race of the pathogen, left California growers without resistant cultivars and with few chemical controls. However, two fungicides have proved effective against the patho- gen and two new resistant cultivars are now commercially available on a limited basis.}

In late 1989, severe epidemics of downy mildew were observed in spinach plantings in coastal California. Most of the cultivars planted at that time were resistant to the three known races of Peronospora effusa. A new race, race 4, of the pathogen caused this outbreak of downy mildew (see California Agriculture, November-December 1990). Since the initial observations of this disease development in 1989, race 4 downy mildew has spread throughout the California spinach growing areas in both coastal and inland counties. Race 4 has also occurred in isolated regions in Texas. All commercial cultivars are susceptible to race 4 , and the spinach industry experienced significant economic losses in 1989 and 1990. Few effective fungicides were available for use against this disease.
Like most agricultural host-pathogen relationships, spinach and $P$. effusa have both undergone many changes over the years. Up until the early 1950s, what is now designated as race 1 downy mildew plagued spinach crops. Researchers at that time developed a new spinach cultivar, 'Califlay', that was resistant to this pathogen. However, in 1958 race 2 appeared in California, rendering 'Califlay' and related cultivars susceptible once again. Researchers and plant breeders countered with 'Early Hybrid 424' and other cultivars; these were resistant to both races 1 and 2 . These resistant spinach cultivars held up for almost 20 years until race 3 was reported in California in 1978. Shortly afterwards, breeders introduced 'Polka', 'Shasta', 'St. Helens' and other cultivars that were resistant to all three races and which are still widely used.

From this history, it is clear that shortterm control options, such as fungicides, are required to help suppress disease levels until new resistant cultivars become available on a wide commercial basis. The purpose of our study was to evaluate the efficacy of fungicides against spinach downy mildew and to evaluate new, potentially resistant cultivars in the field.

\section{Methods}

Fungicides. We conducted fungicide trials during peak downy mildew months
(December through April) in Monterey County in 1990 and 1991. Experiments consisted of separate at-planting and foliar fungicide applications. We applied atplanting treatments to randomized complete blocks with five replications and 20foot-by-20-inch plots. The two treatments consisted of the following: Ridomil 2E ( $0.5 \mathrm{gal} /$ acre) applied to the soil as a single spray over the seed lines at planting, and an untreated control. The Ridomil was watered in with the first irrigation. At location 1 (1990), the susceptible cultivar CX5086 was planted in six seed lines per bed. Location 2 (1991) was planted in the same manner with the susceptible cultivar 'Polka'. We applied no foliar fungicides to the plots for the duration of either trial.

For the foliar fungicide trials (1990), we treated randomized complete blocks with four replications and plots of 25 feet $\times 20$ inches. Treatments consisted of the following: basic copper sulfate ( $4 \mathrm{lbs} / \mathrm{ac}$ ), maneb $80(2 \mathrm{lb} / \mathrm{ac})$, Aliette $80 \mathrm{~W}(2,3$ and $4 \mathrm{lb} / \mathrm{ac})$ and an untreated control. We used

NuFilm-P (6 oz/ac) with the copper and maneb treatments. We applied the materials four times at 7 - to 10 -day intervals. The susceptible cultivar 'Polka' was planted in six seed lines per bed; no at-planting fungicides were applied to the trial area.

For all experiments, we evaluated disease levels by counting the number of 


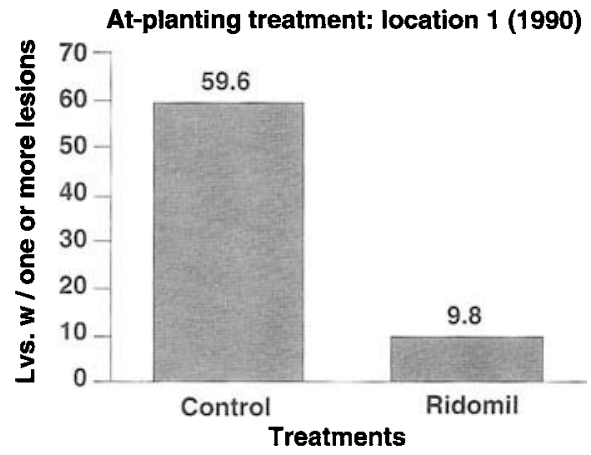

Fig. 1. Disease control achieved by single atplanting application of Ridomil 2E. Fungicide was applied as a banded treatment over seed lines on February 24, 1990. Spinach cultivar was $\mathrm{CX} 5086$. Ridomil rate was $0.5 \mathrm{gal} / \mathrm{ac}$. Evaluation was made at 38 days after treatment, or 17 days before harvest. Ridomiltreated plots were significantly less diseased than untreated plots $(F=94.88 ; P<0.05)$.

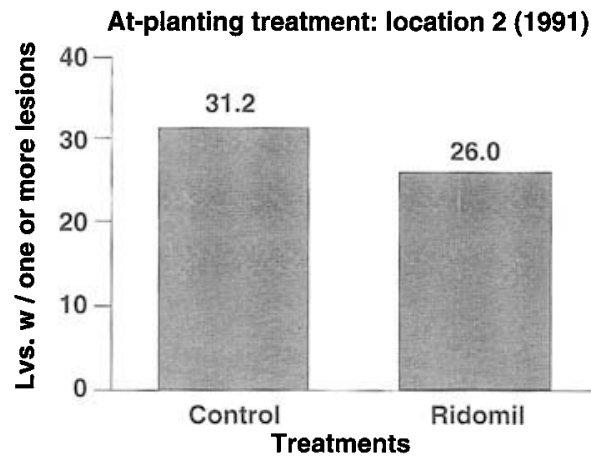

Fig. 2. Disease control evaluation after 80 days of growth. Ridomil $2 \mathrm{E}$ was applied as a banded treatment over seedlines on Jan. 8 , 1991. The spinach cultivar was 'Polka' and the Ridomil rate was $0.5 \mathrm{gal} / \mathrm{ac}$. This evaluation was made 80 days after planting, or 4 days before harvest. Ridomil-treated and untreated plots did not differ significantly in disease severity $(F=2.25 ; P>0.05)$.

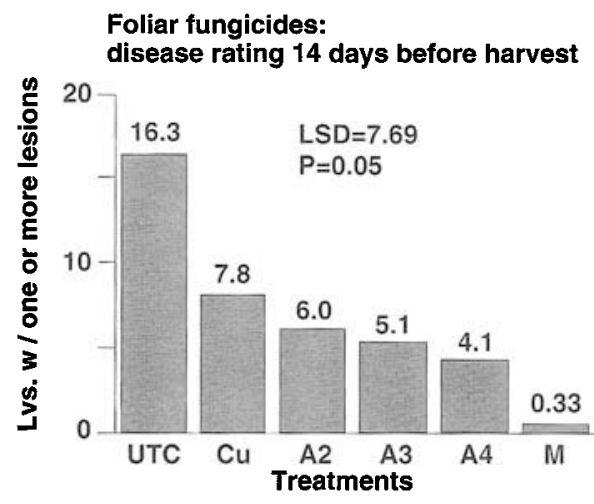

Fig. 3. Disease control achieved after three applications of foliar fungicides (14 days before harvest). Cultivar "Polka" was planted Dec. 1, 1989. Applications were made at 7- to 10-day intervals beginning Jan. 29, 1990. Treatments were as follows: UTC = untreated control; $\mathrm{Cu}=$ basic copper sulfate, $4 \mathrm{lb} / \mathrm{ac} ; \mathrm{A} 2$ = Aliette, $2 \mathrm{lb} /$ ac; $\mathrm{A} 3$ = Aliette, $3 \mathrm{lb} / \mathrm{ac} ; \mathrm{A} 4$ = Aliette, $4 \mathrm{lb} / \mathrm{ac} ; \mathrm{M}$ $=$ maneb, $2 \mathrm{lb} / \mathrm{ac}$. NuFilm-P was added to the copper and maneb sprays. leaves that had at least one downy mildew lesion in a 5-foot-by-10-inch area. Three such areas were rated for each plot, and the results were averaged.

Cultivars. We field-tested numerous commercially available and experimental lines of spinach in order to observe possible resistance or tolerance to race 4 of $P$. effusa. We planted test cultivars into randomized complete blocks with five replications and plot sizes of 10 feet $\times 20$ inches. We evaluated the cultivars by counting the number of leaves that had at least one lesion in a 5-foot-by-10-inch area. Two such areas were evaluated for each plot and the results were averaged. Since race 4-susceptible 'Polka' is one of the most widely planted cultivars, we included it in each trial as a standard variety. We planted cultivars in both Monterey and San Benito counties, and did not apply any fungicides to these trials.

\section{Results}

Fungicides. In the at-planting experiments, Ridomil at $0.5 \mathrm{gal} /$ ac greatly reduced the amount of downy mildew. At location 1 we evaluated the trial at 38 and 52 days after planting ( 17 and 3 days before harvest, respectively). At 38 days, Ridomil-treated plots averaged 9.8 diseased leaves per evaluation area whereas untreated areas averaged 59.6 diseased leaves (fig. 1). New mildew infections did not develop in either Ridomil or untreated plots by the second evaluation period.

However, Ridomil will not persist long enough to provide acceptable disease control if the spinach cropping period is lengthy and the pathogen is active. At location 2 (fig. 2), we evaluated disease levels at 80 days after planting ( 4 days before harvest). Untreated plots averaged 31.2 diseased leaves per area. Ridomil-treated areas averaged 26.0 diseased leaves and did not differ significantly from untreated plots.

We evaluated foliar treatments at 14 days (fig. 3 ) and 2 days (fig. 4) before harvest. Consistently, maneb was the best treatment against downy mildew, keeping the disease at low levels. Aliette was the second best fungicide for control of downy mildew, but it was much less effective than maneb. There was a significant trend regarding Aliette rates; disease levels decreased as Aliette rates were increased from 2 to $4 \mathrm{lb} / \mathrm{ac}$. Basic copper sulfate was least effective in controlling the disease. At this location downy mildew continued to develop after the 14-day evaluation; differences between the treatments became more evident just before harvest (fig. 4).

Cultivars. In the cultivar trial at San Benito County, all the surrounding commercial spinach fields, which were grown without synthetic fungicides, had severe downy mildew disease. We evaluated the cultivars 47 days after planting (fig. 5). 'Bossanova' (1 diseased leaf per area), Bolero' (0.13 diseased leaf), and RS1250 (1.5 diseased leaf) had very low levels of disease compared to the 'Polka' standard (49.3 diseased leaves). Cultivar DMC 6 (33.3 diseased leaves) also had significantly less disease than 'Polka', but was much more infected than 'Bossanova', 'Bolero' and RS1250. All other cultivars in this trial had downy mildew counts that were comparable to or higher than 'Polka'.

Of the resistant cultivars, 'Bossanova' and 'Bolero' are commercially available on a limited basis. RS1250 and DMC 6 are still experimental.

\section{Discussion}

Fungicides. Maneb is an effective fungicide against the spinach downy mildew pathogen. However, over the past several years, concern has increased about possible health risks associated with ethylene bisdithiocarbamate fungicides (EBDCs), such as maneb. The EBDCs have a break-

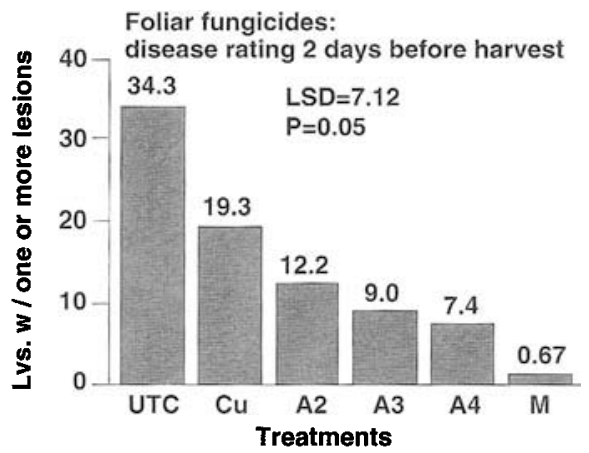

Fig. 4. Disease evaluation 2 days before harvest. The location is the same as in fig. 3. Four applications were made to the crop. Treatments were as follows: UTC = untreated control; $\mathrm{Cu}=$ basic copper sulfate, 4lb/ac; $A 2$ = Aliette, $2 \mathrm{lb} / \mathrm{ac} ; A 3=$ Aliette, $3 \mathrm{lb} / \mathrm{ac} ; \mathrm{A} 4$ : = Aliette, $4 \mathrm{lb} / \mathrm{ac} ; \mathrm{M}=$ maneb, 2 $\mathrm{Ib} / \mathrm{ac}$. NuFilm-P was added to the copper and maneb sprays. As we increased the Aliette rate, disease severity decreased significantly $(y=34.2$ $-14.81 x+2.05 x^{2} ; R^{2}=0.998$ )

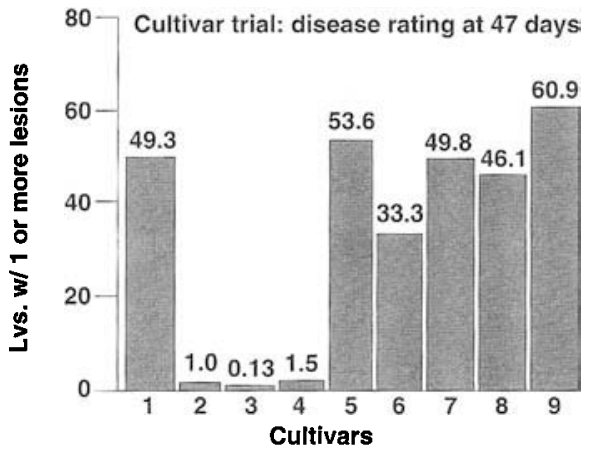

Fig. 5. Cultivars planted in San Benito County. No fungicides were applied during the trial. Evaluation was made 47 days after planting. Cultivars were as follows: (1) 'Polka', (2) 'Bossanova', (3) 'Bolero', (4) RS 1250, (5) DMC 5, (6) DMC 6, (7) 'Triplet', (8) 'Triathlon', (9) 'Triade'. $L S D=11.79 . P=0.05$ 
down product, ethylene thiourea (ETU), which scientists have implicated in tumor development in test animals. Concerns about ETU residues on produce have caused chemical companies to withdraw maneb registrations for many crops. Apparently, when maneb inventories become depleted, this fungicide will no longer be available for use on spinach. Because of the demonstrated efficacy of Aliette, the California Department of Food and Agriculture granted a Section 18 Emergency Registration for the use of this fungicide on spinach

This situation illustrates the difficulties involved with the changing agrichemical picture today. With the loss of an extremely effective material such as maneb, the industry must adopt the use of a less effective and more costly fungicide such as Aliette. Our observations of commercial plantings indicate that, for the most part, Aliette keeps spinach downy mildew at low levels. However, with severe inoculum pressure and favorable environmental conditions, this fungicide may not always keep the disease under acceptable levels.

The at-planting use of Ridomil is an effective, though short-lived, treatment. This material may protect short-season spinach up until harvest. However, the longer season crops grown in the winter or those grown for processing will be unprotected if Ridomil is used alone. Currently, we advise growers to include Ridomil at planting when possible, and then to follow with foliar applications of maneb, if available, or Aliette. Plant-back restrictions for

Ridomil will prohibit use in all situations. Consult product labels and your local agricultural commissioner's office for information on all of these fungicides.

Cultivars. Resistant spinach cultivars that have suitable horticultural characteristics are clearly the preferred means of managing downy mildew disease. Our trials indicate that resistant cultivars now exist. 'Bossanova', 'Bolero' and RS1250 show good resistance to the disease. Since these are newly developed lines and have only been tested and proved this year, the seed companies have just started to produce them on a commercial scale. Presumably, these varieties and others will soon be widely available to the spinach industry. Such cultivars should be relatively free of downy mildew until the next race of $P$. effusa develops.

S. T. Koike is Farm Advisor, Monterey County; R. F. Smith is Farm Advisor, San Benito County; K. F. Schulbach is Farm Advisor, Monterey County.

This work was supported in part by the California Spinach Mildew Research Committee. The authors also thank Jim Correll, Mike Davis, Jack Hills, Al Paulus and Mike Rooney.

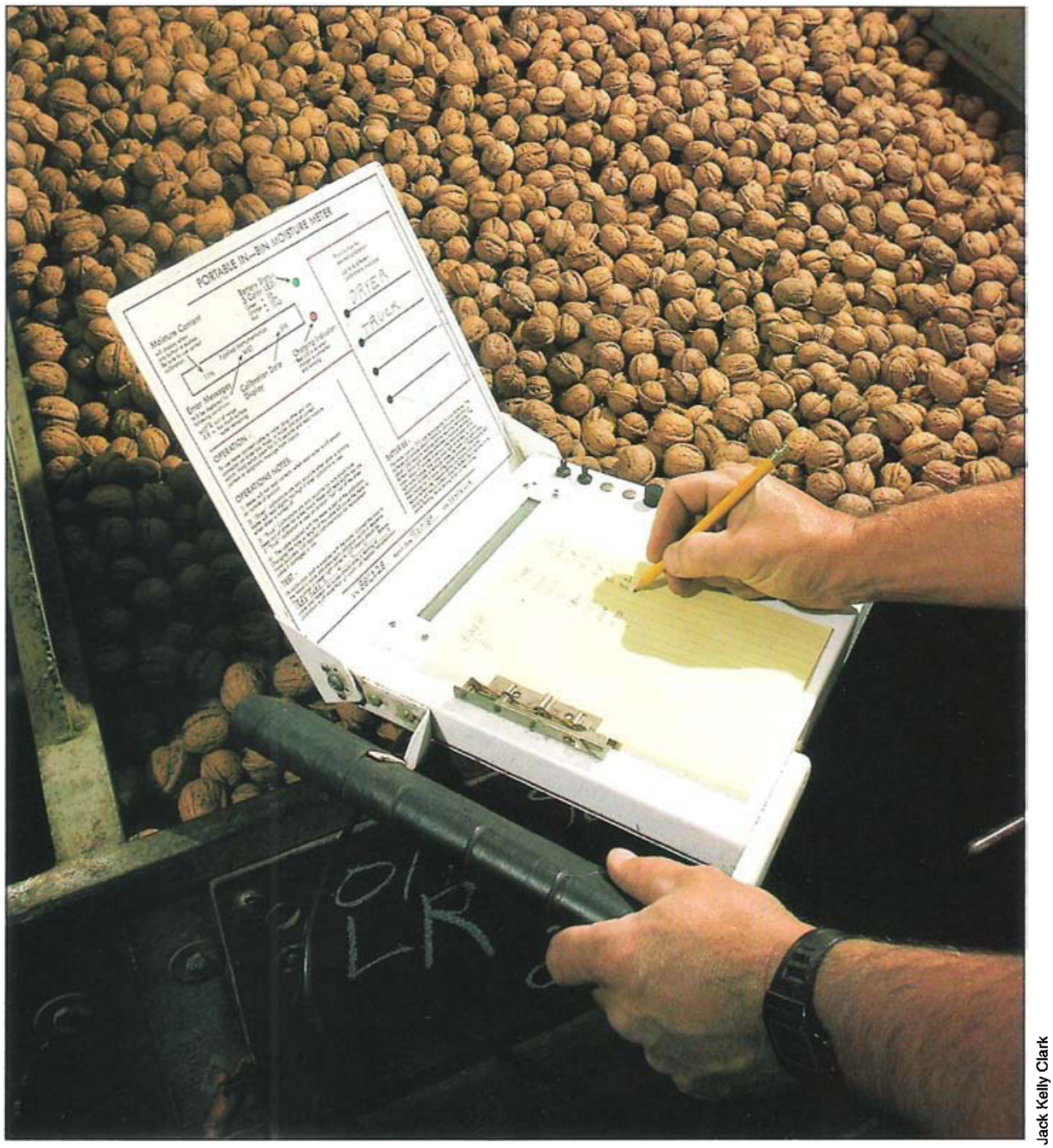

Dryer operator takes moisture reading on full walnut bin using hand held meter. (Moisture readings are displayed as a digital readout, not shown in picture).

\title{
New moisture meter could curb overdrying of walnuts
}

\author{
James F. Thompson $\square$ Joseph A. Grant
}

\section{Tests of a new walnut moisture meter showed that it could help dryer operators prevent over- drying, which in turn would reduce drying time, decrease energy costs and increase revenue.}

mmediately after harvest, walnuts are dried in heated air dryers and, if they are dried too long, they lose more moisture than is desirable. Optimal walnut moisture content for postharvest product life is approximately $8 \%$ on a wet weight basis. Each percentage point of moisture lost below $8 \%$ results in a loss of 21.5 pounds per ton of nuts sold, and overdried nuts are brittle and are subject to damage during handling. Overdrying by several percent- age points also prolongs drying time, increasing energy use and reducing the amount of nuts a facility can dry in a season.

A study of San Joaquin County dehydrators conducted in 1988 (see California Agriculture, January-February 1990) suggested that overdrying is common. In the study, $66 \%$ of loads monitored were dried to moisture contents below $8 \% ; 41 \%$ were dried below $7 \%$ moisture, and $10 \%$ were dried below $6 \%$ moisture. An analysis of walnut samples from a California receiving facility showed that the average moisture content of nuts at delivery was $5.2 \%$ in $1984,5.9 \%$ in 1987 and $5.5 \%$ in 1988 (table 1).

Traditionally, to decide whether nuts are sufficiently dry, several nuts are se- 